\title{
Academic perceptions of the ideal computer science student
}

\author{
Hannah Thinyane \\ Department of Computer Science, Rhodes University, South Africa
}

\begin{abstract}
This paper presents the results of a case study aimed at identifying the skills that lecturers in a computer science department value in an undergraduate student, and to determine if there is a departmental construction of an 'ideal' student. To answer this question, a case study was undertaken in the Computer Science Department at a small university in South Africa. Participants were asked to complete a questionnaire and to take part in an interview to solicit feedback on their notion of an 'ideal' student. This study found that participants valued the following skills within undergraduate student: creativity; computer playfulness; planning, analytical or abstract thinking, and problem solving; introverted personality; engagement in class; working independently; self efficacy; and responsibility. It also found a strong correlation between participant's own performance as a student and their understanding of an 'ideal' student. These results are then discussed within the context of South African Higher Education, where student populations are becoming more diverse. The paper calls for academics to reflect on their own teaching, and the relevance of their practices to the present conditions of transformation in Higher Education in South Africa.
\end{abstract}

KEYWORDS: Higher education, ideal student, computer science

CATEGORIES: K.3.2

\section{INTRODUCTION}

Traditionally seen as 'ivory tower elitist', there is an internationally recognised call [1] for Higher Education Institutions (HEIs) to become more responsive across a number of different fronts. Middlehurst [2] classifies these pressures into four categories: "economic and business dynamics; social and intellectual developments; technological developments; and changes in government policy".

Changes in economic and business dynamics include global trends of governments reducing funding to HEIs 3], yet expecting lecturers "to engage with a greater number and wider diversity of students, and provide them with the knowledge, skills, and dispositions that are deemed necessary for society in the 21st Century" [4, p. 434]. Popular business concepts are also being applied to HEIs, with "fiscal discipline, efficiency and cost-benefit optimisation principles from the world of business ... seen as the key to the transformation of higher education in the direction of greater responsiveness to society" [5, p. 9].

Perhaps the two most significant social and intellectual developments that have been felt within HEIs are due to massification and diversification of the student body. These trends have been felt globally [6] [7], but have been particularly noticeable in post-apartheid South Africa. Since 1993, the number of black and women South Africans, particularly from working class

Email: Hannah Thinyane H.Thinyane@ru.ac.za and rural areas, participating in higher education has increased [8]. Between 1993 and 2005, the total number of enrolments in higher education has increased by $160 \%(473,000$ to 737,472$)$ 9 10. Over the same time period, black student enrolment levels have risen from $52 \%$ to $75 \%$, and women enrolment has risen from $43 \%$ to $54.5 \%$ [10. Despite these increases, government subsidies to HEIs have fallen from $21.5 \%$ in 1991, to $13.9 \%$ in 2002-2004 [3].

Technological innovations have enabled both virtual and physical networks between educators, industry, and government to grow. So much so, that many commentators "base their predictions of expansion, quality and access to higher education on an increased use of new technologies" [2, p. 9]. Many researchers have illustrated that these new technologies (such as advances in connectivity, hardware, and software) have had significant effect on teaching and learning in higher education, in particular in areas such as e-learning, dual-mode teaching, and Information and Communication Technologies (ICTs) within the classroom [11. In some cases, such as within Computer Science and Information Systems Departments, technological innovations necessarily affect the teaching and learning environments as well as content, far more than other non-technical disciplines.

Finally, changes to government policy can also be seen to impact higher education. Under apartheid, HEIs within South Africa were separated, funded, and allocated roles in order to reproduce the apartheid social order [12. Although a thing of the past, the inequalities of this separate development are still felt 
today, as they "continue to condition the current capacities of institutions to pursue excellence, to provide high quality learning and research experiences and equity of opportunity, and to contribute to economic and social development" 8, p. 6]. As also noted by Badat, the current attempts at transforming higher education with South Africa occur within "the context of a formidable overall challenge of pursuing economic development, ... social equity and the extension and deepening of democracy simultaneously" [8, p. 7].

These pressures together reflect the dynamic environment in which HEIs are situated. From the discussion above, it is evident that HEIs have been pressured to change over the past decades, to respond to economic and business dynamics; social and intellectual developments; technological innovations; and changes to government policy. This paper aims to determine the skills that academics within a Computer Science Department at a South African HEI believe are necessary for the 'ideal' student. It also aims to understand if these skills reflect the changes that have been evident in the environments that HEIs operate. To do so, this paper first presents some related work in the fields of teaching and learning. It then describes the research design used throughout this study. The results are then presented and discussed within the context of South African Higher Education.

It is hoped that this paper can contribute to academics' understanding of the driving forces that influence change in the teaching and learning environments that we work in. The paper calls for academics to reflect on their own teaching, and the relevance of their practices to the present conditions of transformation in Higher Education in South Africa.

\section{RELATED WORK}

Educational researchers have contributed to a significant body of work, investigating the influences that teachers perceptions of teaching have on students' learning [13] 14. Pratt [15] developed a taxonomy of five different perspectives on teaching: transmission, developmental, apprenticeship, nurturing, and social reform. Pratt found that of the 2,000 teachers who had undertaken his Teaching Perspectives Inventory [16, over $90 \%$ held only one or two of these perspectives as their dominant view of teaching, and marginally identified with one or two others.

Intertwined into any teaching environment is the construction of a 'good', 'ideal', 'clever', 'intelligent' or 'smart' student. Studies have shown that concepts of intelligence are culturally relative. As Wang, Ceci, Williams and Kopko note:

... cognitive competence is relevant to specific cultures, to the social and physical contexts in which the child participates in organized activities, and to the cultural and societal demands as perceived by the child him or herself [17, p. 17].

Although Wang et al. refer in this paper to child learning, the same can be said for adult learning. Examples can be found in literature of cultural differences in concepts of learning: in America emphasis appears to be primarily on cognitive skills [18; Zambian definitions of intelligence include someone being clever, but also include other factors such as obedience, cooperation, listening and understanding, as well as a prompt response [19; Japanese definitions include a cognitive component, but far more than the US in particular emphasise a "heart and mind for wanting to learn" [20, p. 122], or "socio-emotional prerequisites of competence rather than on knowledge or skills as such" [21, p. 193].

Culture has traditionally been defined as learned and shared behaviour that is common to a community of people 22, p. 169]. This definition is typically applied to groups of people located within a particular area, such as the definition offered by Kroeber and Kluckhorn:

Culture consists of patterns, explicit and implicit, of and for behaviour acquired and transmitted by symbols, constituting the distinctive achievements of human groups, including their embodiments in artefacts; the essential core of culture consists of traditional (i.e., historically derived and selected) ideas and especially their attached values; culture systems may, on the one hand, be considered as products of action, and on the other as conditioning elements of further action [23].

Becher and Trowler broaden the definition of culture by applying it to different disciplines within academia. In "Academic Tribes and Territories", Becher and Trowler 24 illustrate the existence of these learned and shared human patterns and practices which are unique within academic disciplines, such as: gatekeeping practices; the nature of innovations specific to disciplines; communication patterns; career trajectories; and even the sports and other pastimes that are preferred by different "tribes". Within the "tribe" of computer science, a number of studies have been undertaken to determine the skills that make an 'ideal' programmer. Early studies 25] 26] concentrated on the Myers-Briggs indicators to determine the psychological preferences of programmers. These studies had mixed findings, with Lyons finding the majority of programmers to be "thinking judging", and Sitton \& Chmelir finding the majority to be "thinking perceiving". From a skill perspective, a number of other studies have highlighted the importance of self-efficacy [27] [28] as a key characteristic of computer programmers. Researchers have found a correlation between "computer playfulness" 29] 30] and stronger feelings of self-efficacy.

If we return to our broadening definition of culture and take a sociological perspective on the term, one of the leaders in this area is Bourdieu [31]. One of his key concepts is "habitus", the internal structures that determine how a person acts and reacts to the world. We acquire this "habitus" first from our families, but then also from our schooling, that through habituation, repetition, and affirmation of certain behaviours (attitudinal, affective, cognitive, and bodily) forms this 
largely unconscious disposition. Bourdieu argues that although "habitus" is constructed on an individual basis, shared experiences in the world will produce a collective "habitus". Another concept that Bourdieu defines is "doxa", which illustrates that a person's beliefs seem to have "a quasi-perfect correspondence between the objective order and the subjective principles of organization [with which] the natural and social world appears as self evident" [31, p. 156]. That is, the ways that individuals have learnt to perceive, evaluate, and behave become accepted and considered 'normal' to themselves [31, p. 164]. As further explored by Throop and Murphy [32, p. 189], "it is the successful 'internal' replication of structure that leads individuals to mistake 'objective structures' as 'natural', as they remain ignorant of the ever-present dialectical reconstitution of internal and objective structures".

What Bourdieu is perhaps most known for is his application of these concepts within the sphere of education, particularly the public education system in France 33 . Bourdieu sought to explain why students from working class backgrounds continually performed worse than their upper class peers. He concluded that the students themselves were not to blame, but that the curriculum itself favoured students who had been exposed to upper class culture in the construction of their "habitus". Using Bourdieu's terminology, it was because of the students' lack of 'cultural capital' that working class students did not perform as well as their upper class peers. He believed that it was for this reason that education systems could reproduce themselves and perpetuate inequality.

This section began by exploring the interplay between teachers' differing perspective on teaching and students' approaches to learning. It illustrated that different cultures have their own concept of an 'ideal' student, and then expanded the definition of culture to include academic disciplines. The next section discusses the design of the experiment that was undertaken to determine the concept of an 'ideal' student within the Computer Science Department at Rhodes University.

\section{RESEARCH DESIGN}

The main research question that was addressed in this study was: what are the skills that lecturers in a computer science department value in an undergraduate student, and is there a departmental construction of an 'ideal' student. In order to answer these questions, the following subsidiary questions were posed:

- What skills do lecturers believe are critical in an 'ideal' computer science student?

- Is a lecturer's construct of an 'ideal' student influenced by their own performance as a student?

- Is there a consensus across the department of an 'ideal' student?

\subsection{Methodology: case study}

Quantitative and qualitative studies are both valuable in providing evidence across the study of different phenomena. On the one hand, quantitative studies use large numbers of (typically) randomly selected participants to study a specific group of variables. Quantitative studies can be used to produce generalizable findings that can be applied to other populations, but in doing so they lose much of the richness in the details of the studied activity or phenomena [34. On the other, qualitative studies provide rich causal explanations, but deal with a small number of cases. A disadvantage of qualitative studies is that they are less generalizable. However, when a study is "contextualized and carefully described ...then others can consider its usefulness in other contexts and examples" [35, p. 191].

This research uses a qualitative approach and can be seen as a case study. A case study is defined as a "strategy for doing research which involves an empirical investigation of a particular contemporary phenomenon in its real life context using multiple sources of evidence" [36, p. 52]. This approach allows researchers to focus on the primary strength of case study methodology, that it "enables the uncovering of events or processes that one might miss with more superficial methods" [37, p. 238]. Case study research does have its drawbacks though. Social realist research, which underpins the thinking in this study explicitly holds that:

No individual-level intervention works for everyone. No institution-level intervention works everywhere. The net effect of any particular programme is thus made up of the balance of successes and failures of individual subjects and locations. What this points to is the need for a careful look at subject and contextual difference in terms of who succeeds and who fails within any programme [38, p. 30-1].

This reporting therefore does not claim to generalise, but to highlight skills that are considered as essential in an 'ideal' computer science student within a particular context.

\subsection{Participants}

This research is based in the Computer Science Department at Rhodes University, a relatively small (7200 students) public university in South Africa. At the time of the study taking place, there were 12 full time academic staff members in the department. As this research aimed to investigate a departmental construction of an ideal student, only members of staff who had been employed for at least one full year in the department took part in the study $(n=10)$. The researcher herself is part of the department, and thus did not participate in the study ( $\mathrm{n}=9,3$ females, 6 males).

\subsection{Survey instruments}

A survey of literature was first undertaken to determine the core skills and competencies that are suggested for 
computer science graduates. This review included a number of different sources such as ACM / IEEE curriculum review documentation, the Rhodes University Computer Science Department's Vision and Values statement, and peer reviewed journals and conference papers in the field [39] 40, 41, 42, 43] 44, 45] 46]. This review resulted in a list of 96 skills which were then analysed and duplicates were removed. The remaining 63 skills were then categorised as follows: interpersonal skills, leadership skills, self-management, thinking skills, workload management, information handling, personal qualities, and handling the unknown.

Four student scenarios were then developed based on the skills from the list, with each student presented with a number of positive skills and one negative characteristic. The four student scenarios are: Andrew, a team player who is reliable, good at time management, but not creative; Bridget, a very introverted student who is analytical, insightful, and good at written communication; Cynthia, an extremely creative student who is terrible at time management; and David, an extrovert who is confident, and an independent and critical thinker, but can become aggressive and critical. These four scenarios represent a systematic variance in gender, degree of extroversion / introversion, and communication skills.

A two page questionnaire was developed with one page based on the four scenarios, and the second page based on the skills (see Appendix A). The first page asked participants to rank the four students from 'ideal' to 'weak' student (on a scale of 1 to 4 respectively), and to justify their rankings. The second page asked participants to select at most three skills from each category that they felt were important in a student. It also gave participants the chance to include any other skills that they felt were important to each of the categories. The scenarios and skill list were employed together in the survey, and as will be described in the next subsection, were followed by an interview to attempt to increase the validity of the findings, by incorporating what Denzin [47] refers to as methodological triangulation.

\subsection{Method and analysis}

Prior to the study, permission was granted from the Computer Science and Information Systems Ethics Committee, and each participant signed a consent form. When consent was given, participants were provided with a copy of the questionnaire and asked to notify the researcher when it was completed. On completion of the questionnaire, each participant was interviewed separately in order to solicit more information on their rankings; their construction of an 'ideal' student; and their opinion on a departmental construction of an 'ideal' student. The average duration of each interview was 10-23 minutes, and followed a semi-structured interview schedule with a series of key questions that commenced with non-emotive questions aimed at putting interviewees at ease, and then progressed to more theory-laden questions. In this context, theory-laden refers to theories from literature and from the researcher's own reflection that could impact the construction of an 'ideal' student.

All interviews were recorded using a Samsung Galaxy i9000s and compressed to MP3 format. Interviews were then transcribed verbatim by the researcher. Transcriptions were sent to participants for member checking to improve the accuracy and validity of the study. Questionnaires were captured and entered into Microsoft Excel for later incorporation in the data analysis phase. Transcripts and questionnaires were coded to maintain the anonymity of participants, whilst allowing a correlation between the participants' two forms of response.

Qualitative data analysis can involve using topdown, bottom-up, or a combined coding approach [48. This research used a combined approach. At the beginning of the process, a top-down approach was used in that questionnaire responses were analysed and all skills that were ranked as important by at least $50 \%$ of the participants were included as categories. Table 1 shows the 15 skills that were ranked as important by participants and the frequency that the skill was selected. The frequency was calculated as a percentage of the number of participants who selected skills for that grouping (regardless of how many skills they selected per grouping). The brackets following each table entry indicates the category under which the skill appeared in the questionnaire:

- L - Leadership

- SM - Self Management

- TS - Thinking Skills

- WM - Workload Management

- IH - Information Handling

- PQ - Personal Qualities

- HU - Handling the Unknown

- IS - Interpersonal Skills

During the analysis, a bottom-up approach was also used to derive additional categories based on the content of the data [48, p. 32].

The researcher made use of the constant comparative analysis technique [49] to analyse transcripts and questionnaire responses. NVivo, a qualitative software package, was used to perform all coding and analysis of qualitative feedback. Once all coding was completed, reports were drawn from NVivo on the various themes that will be presented in the following section.

\section{RESULTS}

This section presents the results of this case study, organised as follows: student scenario rankings; 'ideal' student skills; influence of own experience as a student; and departmental construct. Results for these three questions are preceded by a description of the student scenario ranking.

\subsection{Student scenario ranking}

Table 2 presents a summary of the participants' rankings of each of the four scenarios. From the left column, this table presents the mean, median, mode, minimum, and maximum rankings across all participants. All 
Table 1: Top-ranked skills

\begin{tabular}{|ll|ll|}
\hline Initiative (L) & $78 \%$ & Self-motivation (SM) & $78 \%$ \\
Abstract thinking (TS) & $67 \%$ & Dedication (L) & $67 \%$ \\
Innovation (L) & $67 \%$ & Organization (WM) & $67 \%$ \\
Analysis and synthesis (TS) & $56 \%$ & Good written communication (IH) & $56 \%$ \\
Open to constructive criticism (IS) & $56 \%$ & Problem solving (TS) & $56 \%$ \\
Responsibility (SM) & $56 \%$ & Responsibility (PQ) & $56 \%$ \\
Seeing the larger picture (IH) & $56 \%$ & Time management (WM) & $56 \%$ \\
Ability to work independently (IS) & $56 \%$ & & \\
\hline
\end{tabular}

scores are ranked on a scale of 1 to 4 , where 1 represents an 'ideal' student, and 4 represents a 'weak' student.

As Table 2 shows, out of all of the students, Bridget was ranked the closest to 'ideal', being ranked in position 1 or 2 by all participants. As such, her mean ranking was significantly lower than any of the other student scenarios. David was closest behind her, with a range of 1 to 3 across participants. Andrew and Cynthia were ranked very similarly, with identical median, mode, minimum, and maximum rankings. The only difference was in their mean, with Cynthia receiving a lower (and therefore closer to 'ideal') ranking than Andrew.

It is interesting to see that the descriptions of the two highest ranking students made specific mention of their analytical ability, and differed in how introverted they were. Bridget, the top-ranked student, was a classic introvert, who does not like oral communication and is most comfortable out of the spot light. David on the other hand is the classic extrovert, who is great at oral communication and loves to be the centre of attention. The descriptions of Cynthia and Andrew also play off of each other, with Cynthia being creative with poor time management skills, and Andrew having great time management skills, but not being creative.

These rankings cannot be used alone to identify 'ideal' skills, as each student represents a trade-off. Participants commented on a number of occasions that they struggled to choose one participant over another, as each had skills that were not 'ideal'. This question aimed instead to explore the combination of skills that were preferred. The following section describes findings for individual skills as ranked by participants.

\section{2 'Ideal' student skills}

Due to the small sample size, statistical tests could not be conducted to establish the statistical significance of participant rankings of skills (Table 11). Instead, this section focuses on the qualitative feedback obtained during the interviews. A large number of the comments from participants in interviews identified additional qualities of 'ideal' students that had not been selected in their questionnaires, and were coded using the bottom-up approach described in Section 3.4 This section provides an overview of the skills, ordered by the frequency that they were mentioned in the interview.

\subsubsection{Creativity}

Although most participants indicated that creativity was essential, a number of them expressed concern that when left unchecked, this could have an impact on deadlines. This concern was perhaps influenced by Cynthia, one of the students from the scenarios on the questionnaire who was creative but missed her deadlines. One participant commented:

I love the creativity personally of Cynthia, but her inability to complete things on time and the sort of random creativity makes for unfortunately not a good computer science student. They tend to not get in depth into the course but go off on tangents. So the foundation work is really not there. She probably won't be a very good computer science student.

When answering questions about the skills that he felt were required in students, another participant noted that he was particularly looking for skills that could not be taught to students but had to be present already. From his perspective,

... the inability to be creative is quite a core thing and it represents something that is difficult to instil in a student if it's not there already

Creativity can also be viewed as being related to an autotelic personality, where the student has an internal motivation and is driven by curiosity. One participant described the importance of an autotelic personality for computer science students saying:

You get into the zone where you are organising things and they all are kind of working ... So this idea that you sit up and immerse yourself in quite hard conceptual stuff and lose track of time. I think that is what most really good computer scientists do. I think once you get into something, it just takes you over and you're in a different space completely 
Table 2: Student scenario ranking

\begin{tabular}{|l|lllll|}
\hline & Mean & Median & Mode & Min & Max \\
Andrew & 2.778 & 3 & 4 & 1 & 4 \\
Bridget & 1.556 & 2 & 2 & 1 & 2 \\
Cynthia & 2.667 & 3 & 4 & 1 & 4 \\
David & 2.556 & 3 & 3 & 1 & 3 \\
\hline
\end{tabular}

... And so the idea of an autotelic personality and getting into the flow or the zone of things looks like an important thing about being creative when you build software.

\subsubsection{Computer playfulness}

Computer playfulness has been defined in literature as "the tendency to interact spontaneously, inventively, and imaginatively with microcomputers" [27, p. 417]. This skill was mentioned by a number of different participants, and can be seem to be complementary to creativity. One participant described her experience with playfulness:

... the people who become good programmers and computer scientists are those that like playing with programs. And actually it doesn't matter if you're getting the pracs in on time because what you find is in the exams, because they're interested and because they've played, they tend to be able to come up with good solutions.

Participants also correlated a lack of playing to a superficial understanding of course content. A number of participants described deep approaches to learning within computer science as playing with programs.

I ranked Andrew lowest because of the fact that he sounds like he's very good at handling work that he's given, but he doesn't go much beyond that. What you tend to find with those people is when you ask them to extend themselves, they struggle to do anything different, because they've done the prac and for the test they've memorised the prac and what they did in class. But they're not finding it so easy to apply what they learnt to anything else.

\subsubsection{Planning, analytical or abstract thinking, and prob- lem solving}

Planning, analytical or abstract thinking, and problem solving have been grouped together, as they refer to what are typically considered as the cognitive skills required of a computer scientist. As could be expected, these skills ranked highly with participants.

I felt that an analytical deep thinking student was someone who would do well in undergraduate courses, because they would think hard about the material, analyse it, and then with that analytical capability be able to provide something in the exams that was good.

Another participant emphasised the importance of abstract thinking, referring to it as one of the most important skills in a computer science student:

So for me the two most important things are abstracting and reasoning in an abstract form. And the ability of taking the empirical nature of the beast and then use it together with the abstract thinking.

\subsubsection{Extrovert vs. introvert}

Computer scientists are typically portrayed as introverts who lack in social skills [50]. Participants in this study agreed with the stereotype, with a number of them commenting that the introverted stereotypes represented more typical computer science students. One participant who had ranked David, an extrovert, as their 'ideal' computer scientist was disconcerted by this part of his character and remarked saying "an extrovert shouldn't be a typical computer scientist".

Another participant rationalised his preference for introverts as programmers, referring to the deep thinking skills that are required for computer science:

I'm not sure that extroverts are going to make the best programmers. I think a lot of computer science happens reflectively in your head. So people who reflect ... and think quietly and organise ideas I think make better computer scientists.

One of the participants focused on a particular aspect of the introvert Bridget's personality, in that she lacked oral communication skills. He described that while this lack of skill was quite common in undergraduate computer science students, it typically would blossom in postgraduate studies or a work environment.

Although they don't specifically refer to extroverts and introverts, one participant showed concern about students who 'need' to work with other people. In her comments, she referred to qualities of introverted and extroverted students, with particular reference to the typical introverted personalities in a computer science class:

You need to like to do things independently. I think that actually it is very important in this field, because it tends to attract people who are nerdy etcetera and like to work alone. So if you are somebody who needs 
to work with other people, what you'll often find is you become isolated in a computer science class because everyone is doing their own thing and there's this competitive vibe going, particularly amongst the better students, and if someone is collaborative rather than competitive, it makes it difficult to fit into that.

This comment refers to feelings of isolation that the participant believes could be felt by an extrovert in a class of introverts.

\subsubsection{Engagement in class}

The next most frequently discussed topic was engagement in class. A surprising number of participants referred to this skill when describing their 'ideal' computer scientist. One of the questions on the questionnaire asked participants if there were any students they could think of that they thought were 'ideal' computer science students. One participant in particular named two students who he felt were 'ideal'. When asked what characteristics the students shared, he first mentioned their intelligence, but then commented saying "both of them will kind of interact with you and talk with you". Another participant made a correlation between 'geeky' students and willingness to participate in class:

This is going to be stereotypical but they tend to be a little bit geeky. In other words they don't really care what other people think of them in terms of asking questions. They don't care if they put their hand up three times in a row. They are focused on the material.

Other respondents felt that engagement in class was a sign of a deeper approach to learning for a course:

Stuff like the dedication and the hard working, and enthusiasm comes through in the being prepared to interact and talk about things ... being prepared to stick your neck out and answer questions in class.

\subsubsection{Working independently}

A number of participants described the importance of working independently. Participants used the word independence from two different perspectives: independence as opposed to working in a team, and independence as opposed to working only as directed by the lecturer. From the first perspective, participants were wary of students only working in teams, as they did not believe that it would provide students with enough opportunity to develop their own skills:

I don't think you can really become a good computer science student if you really only work in teams ... To a large extent there are certain habits that you have to get into you have to develop alone. And once you have those, you and someone else who has those can work together, or you can help them to develop them.
Participants expressed an understanding that learning was a social process, and that asking them to work in pairs and talk through a problem was beneficial, but were still hesitant to allow students to work in groups for a large portion of their assignments.

From the second perspective of working independently, a number of participants commented on student engagement with class material and showing initiative to work by themselves. This could be seen as a similar skill to 'computer playfulness' as described in Section 4.2 .2 .

... if you just rely on what you're given and you don't put any effort in yourself then you're not going to get anywhere.

The ability to work independently is really important ... To act like an adult and do stuff.

\subsubsection{Self-efficacy}

Literature has often showed that people's positive belief in their own skills and capabilities has a positive implication on their performance 30. When describing his rankings for the four stereotype students, one participant felt that the student Bridget represented a gender stereotype that he had experienced in computer science:

The scenario [Bridget] paints out that she is insightful and I think it goes to an interesting characteristic around self confidence, which in many ways is gender stereotyped in my experience. Young women coming through the computer science program, some of them are very confident, but they need constant reassurance that they can do things. And they often know the answer but are unwilling to share it in the off chance that they are wrong. Someone like [Student] had a fantastic work ethic, highly organised, and was really good, but very insecure about her own ability.

In referring to this need for constant reassurance, this participant highlighted that an 'ideal' student would demonstrate self efficacy.

\subsubsection{Responsibility}

Responsibility was also suggested as a skill for the ideal computer science student. One participant described their reason for highlighting this skill saying:

Because I think if you are responsible it covers a lot of the other aspects. Because you are responsible to yourself for what you do, and responsible towards others. It covers a lot of the other evils."

\subsection{Influence of own experience as student}

This section explores answers to the research question "Is a lecturer's construct of an 'ideal' student influenced by their own performance as a student?". To do so, participants were asked how they believe their lecturers found them when they were a student. They were also 
asked if they could relate to any of the four student scenarios described in Section 3.4. In response to these questions, all participants except for one $(88.89 \%)$ said that they were most like the student they had ranked as ideal (66.67\%), or a combination of their ideal student plus the antithesis of their ideal student (i.e., Andrew-Cynthia, Bridget-David) (22.22\%). The one participant $(11.11 \%)$ who did not rank in this way responded saying he was unlike any of the scenarios. These rankings show a strong correlation between lecturers' individual construction of an 'ideal' student and their own performance as a student.

A number of participants described that they questioned themselves when ranking students, with one participant commenting that he asked himself "Am I just looking for students who are like me?". Another participant made some particularly insightful comments regarding the ranking of 'ideal' students:

The parts of me that I am happy with and feel comfortable with are what I like to see in students as well. And it particularly came out when I was thinking of Cynthia. She epitomises a person who is very different from me. And can I really see the good parts of that? To answer your question then, a lot of how I was as a student is what I strived for in what I've put down here.

This comment correlates with Bourdieu's findings of education systems reproducing themselves and perpetuating the culture of the department or educational institution (Section 3.4).

\subsection{Departmental construct}

The final question this research sought to address was is there a departmental construct of an ideal student. When asked if they thought that other staff members had the same perceptions of what an ideal student was, all participants responded that they did not believe this was the case. Two participants $(22.22 \%)$ believed that there may be a "loose correlation" between skills, but not across the whole department. The results presented in the previous sections confirm these suspicions, that there are some skills that are rated high by participants, but there is no consensus across all participants.

One third of the participants explicitly mentioned that the diversity in constructions of 'ideal' students amongst staff was a positive factor. One participant noted that the diversity in staff and the diversity in the students were beneficial:

I think it's fortunate that students get a cross section of teachers and we get a cross section of students. You can't win them all, and they're a probably some students you can relate to and you can pull up, but there are some students that you can't ... I always hope that for every student that I manage to get a spark in to, or from every one that I don't that there have been other people in the department who get them over that. Because if you are a student who doesn't relate to any one at all, with no staff as role models, it must be very hard. The students will be left behind.

\section{DISCUSSION}

Researchers from a vast array of disciplines have been interested in investigating and understanding intelligence. Dweck [51, p. 6] approaches the topic from a psychological perspective and notes that there are typically two views on intelligence that are held: fixed mindset, or growth mindset. From a fixed mindset, a student is viewed as having "a certain amount of intelligence, a certain personality, and a certain moral character". This mindset does not allow for change (improvement) and leaves the student in a position of helplessness as they cannot do anything to change it if they just so happened to be born "unintelligent". From a growth mindset however, your basic qualities of intelligence, personality and moral character can be improved through effort. After twenty years of research, Dweck found that students with a growth mindset were more willing to try new things, to pick themselves up when they failed, and to try again. When a student's self-worth is tied up in being "smart", and when a teacher only praises and rewards correct answers, Dweck found that students either become lazy and rely on their intelligence to pull them through; or they shy away from new or difficult tasks in case they are not good at them. When a student has a fixed mindset and believes they are not one of the "smart" ones, then they may be so scared to be wrong that they don't try at all.

When applied to teaching, the fixed/growth mindset and importance of practice provide some interesting connections with computer playfulness, creativity, and to an extent working independently. Perhaps most obviously, computer playfulness, creativity and working independently can be seen as practicing. In promoting skill practice, students would gain experience and develop their computer science skills. The question becomes, within a computer science curriculum then how could this be encouraged? Computer science students are motivated by the same thing as other students: to motivate students to practice typically there must be marks allocated [52]. This is interesting as it changes the dynamics of computer playfulness and working independently. No longer would these skills be employed out of a place of curiosity or creativity (intrinsic motivation), but out of obligation (extrinsic rewards). Instead of seeing this through a negative lens, by aligning outcomes, teaching, and assessment [53, a lecturer could take advantage of students motivation and encourage participation in creative or playful exercises.

Dweck's research also presents some interesting challenges. For example, how can effort be rewarded in a teaching environment? How can we acknowledge the "smart" students without setting them up to rely on their intelligence? As mentioned earlier, students are typically motivated by marks, and focus on learning skills or theories that are assigned marks. To reward 
the process rather than just the outcome of learning, marks must then be allocated for the process.

Another skill that was mentioned by a number of participants was student engagement. Given the particular context of South Africa, and particularly previously disadvantaged schools within South Africa, this can be a culture shock for students. Teaching in previously disadvantaged schools tends to be teacher dominated, where students are taught that to question a teacher is to question their authority 54. This mismatch in expectations between staff and students has been documented across different countries and academic departments [55] 56] 57. To rectify this, lecturers can engage students in discussions about their expectations for the course. As well as providing clarifications to students, lecturers can use this process to demonstrate active engagement with issues, mentoring students in ways of participation within academic discourse [58].

It is important to note that this research is framed as a case study, and as discussed in Section 3.1, disadvantages of this research methodology include the lack of direct generalizability of findings 38. It is interesting to note however, that the skills that were selected as important by participants mirror findings from other studies 27, 30, 39, 45.

The participants' own experience as a student can be seen to have an impact on the skills that they value in their students. On reflection, it can be seen that this process of valuing, and training students in particular skills replicates the existing status quo within a system across each new intake of students. With the massification of university both internationally and across Africa [10], there have been some interesting consequences. Firstly, the increase in student numbers has also brought changes to the composition and aspirations of the student body 32 . Students entering higher education no longer enrol for the same reasons as the academics that teach them did [8]. This has the effect that their motivation to participate in classes may also be of a different level to what the academic may presume from their own experience.

From a diversity perspective, the increasing levels of participation amongst previously underrepresented groups have interesting consequences if not matched by an equally diverse academic body. If all academics were to act to (subconsciously) replicate themselves in each new cohort of students, then previously underrepresented groups may struggle.

There is therefore a need for academics to be aware of the changes in the composition of the student body and students' motivation for enrolling in higher education. As described earlier, due to massification and diversification within the higher education system, an academic can no longer expect students to have the same background or motivation as they themselves once did. Academics must be aware that their notion of an 'ideal' student is in most cases based on their own experience, and if changes are not made to this notion, we will merely replicate the pervasive gaps that exist in the current higher education system. Within the context of the South African higher education system this is particularly important. Due to the legacy of apartheid within the country, there is a transformative agenda within higher education aimed at, amongst other things, working towards diverse student populations that are more representative of the national demographics [1].

Rodriguez calls educators to take up the role of what he refers to as "cultural warriors' for social change" [59, p. 278]. Rodriguez notes that all work in teaching and learning education either reproduces or challenges the status quo. In this paper, he cited a wide range of studies that had been undertaken with evidence of cultural issues affecting teacher's pedagogies or classroom practice, highlighting their resistance to pedagogical change. Rodriguez highlights the importance of dealing with resistance to change in new teachers who have had "an apprenticeship of observation on how to teach" [59, p. 286] by their own school experience.

To become more effective teachers within a system that is known for failing its students 60 61, we must therefore reflect on our own role in the education process, by asking ourselves the following questions posed by Rodriguez:

... we can begin to (re)define our roles as cultural warriors and begin to muster the courage to hold the other's gaze - the courage to ask ourselves: Is our teaching and research having the kind of socially transformative effect the present condition of education demands? In what ways can we rethink our teaching and research practices so that gender issues and multicultural education are more directly addressed? Are issues of gender and diversity only addressed in the classes of colleagues who do not look like me? [59, p. 288]

\section{CONCLUSION}

This paper has presented an investigation that aimed at identifying skills that staff at a computer science department in South Africa found were crucial within an 'ideal' computer science student. These skills include: creativity; computer playfulness; planning, analytical or abstract thinking, and problem solving; introverted personality; engagement in class; working independently; self efficacy; and responsibility.

This paper also explored a pattern that emerged amongst participants in the study, where their perspective on an 'ideal' student was found to be influenced predominately by their own performance as a student. This finding can be seen as validation of Bourdieu's notion of academic culture replicating itself and perpetuating the culture of the academic department or higher education institution. This was explored deeper given the particular context of massification and diversification within South African higher education. Finally the paper challenges us as academics to reflect on our own teaching practice and the relevance of our 
teaching to the present conditions of teaching within South Africa.

\section{REFERENCES}

[1] I. Moll. "Curriculum responsiveness: The anatomy of a concept". Curriculum responsiveness: Case studies in higher education, pp. 1-20, 2004.

[2] R. Middlehurst. "University challenges: Borderless higher education, today and tomorrow". Minerva, vol. 39, no. 1, pp. 3-26, 2001.

[3] UNESCO. "Commitment to education: public spending". Human development report 2006. Beyond scarcity: Power, poverty and the global water crisis, 2006.

[4] C. Hodgkinson-Williams, H. Slay and I. Siebörger. "Developing communities of practice within and outside higher education institutions". British Journal of Educational Technology, vol. 39, no. 3, pp. 433-442, 2008.

[5] M. Singh. "Re-Inserting the 'Public Good' into Higher Education Transformation". In Kagisano. Council on Higher Education Discussion Series, 2001.

[6] M. Pan and D. Luo. "A comparative analysis on models of higher education massification". Frontiers of Education in China, vol. 3, no. 1, pp. 64-78, 2008.

[7] S. Guri-Rosenblit, H. Šebková and U. Teichler. "Massification and diversity of higher education systems: Interplay of complex dimensions". Higher Education Policy, vol. 20, no. 4, pp. 373-389, 2007.

[8] S. Badat. Higher Education Transformation in South Africa Post 1994: Towards a Critical Assessment. CEPD, 2007.

[9] D. of Education. Education statistics at a glance in South Africa in 2005. Department of Education, October 2006.

[10] C. on Higher Education. South African higher education in the first decade of democracy. Council on Higher Education, 2004.

[11] R. Mills and A. Tait. The convergence of distance and conventional education: Patterns of flexibility for the individual learner. Routledge, 2002.

[12] S. Badat. "Redressing the apartheid legacy of social exclusion: social equity, redress and admission to higher education". Presented at SANORD 2009: Inclusion and exclusion in higher education, Grahamstown, 2009 .

[13] K. Trigwell, M. Prosser and F. Waterhouse. "Relations between teachers' approaches to teaching and students' approaches to learning". Higher education, vol. 37, no. 1 , pp. 57-70, 1999.

[14] D. Kember and L. Gow. "Orientations to teaching and their effect on the quality of student learning". The Journal of Higher Education, pp. 58-74, 1994.

[15] D. D. Pratt. "Good teaching: One size fits all?" New Directions for Adult and Continuing Education, vol. 2002, no. 93, pp. 5-16, 2002.

[16] D. D. Pratt and J. B. Collins. "The teaching perspectives inventory (TPI)". In adult education research conference, Vancouver, BC. 2000.
[17] W. Wang, S. Ceci, W. Williams and K. Kopko. "Culturally situated cognitive competence: A function framework". In R. Sternberg and E. Grigorenko (editors), Culture and competence: Contexts of life success, pp. 225-250. Washington DC: American Psychological Association, 2004.

[18] S. Harkness, M. Blom, A. Oliva, U. Moscardino, P. O. Zylicz, M. R. Bermudez, X. Feng, A. Carrasco-Zylicz, G. Axia and C. M. Super. "Teachers' ethnotheories of the 'ideal student'in five western cultures". Comparative Education, vol. 43, no. 1, pp. 113-135, 2007.

[19] R. Serpell. The significance of schooling: Life-journeys in an African society. Cambridge: Cambridge University Press, 1993.

[20] J. Li. "Chinese conceptualization of learning". Ethos, vol. 29, no. 2, pp. 111-137, 2001.

[21] L. Shapiro and H. Azuma. "Intellectual, attitudinal and interpersonal aspects of competence in the United States and Japan". In R. Sternberg and E. Grigorenko (editors), Culture and competence: Contexts of life success, pp. 187-206. Washington DC: American Psychological Association, 2004.

[22] J. Useem, R. Useem and J. Donoghue. "Men in the middle of the third culture: The roles of American and non-Western people in cross-cultural administration". Human Organization, vol. 22, no. 3, pp. 169-179, 1963.

[23] A. L. Kroeber and C. Kluckhohn. "Culture: A critical review of concepts and definitions." Papers. Peabody Museum of Archaeology 83 Ethnology, Harvard University, 1952.

[24] T. Becher and P. Trowler. Academic tribes and territories: Intellectual enquiry and the culture of disciplines. Berkshire: Open University Press, 2001.

[25] S. Sitton and G. Chmelir. "The intuitive computer programmer". Datamation, vol. 30, no. 16, pp. 137140, 1984.

[26] M. Lyons. "The DP psyche: An international survey sheds new light on the personalities of data processors". Datamation, vol. 31, pp. 103-107, 1985.

[27] J. Webster and J. J. Martocchio. "Microcomputer playfulness: development of a measure with workplace implications". MIS quarterly, pp. 201-226, 1992.

[28] T. Hill, N. D. Smith and M. F. Mann. "Role of efficacy expectations in predicting the decision to use advanced technologies: The case of computers." Journal of applied psychology, vol. 72, no. 2, p. 307, 1987.

[29] J. J. Martocchio and J. Webster. "Effects of feedback and cognitive playfulness on performance in microcomputer software training". Personnel Psychology, vol. 45, no. 3, pp. 553-578, 1992.

[30] D. Potosky. "A field study of computer efficacy beliefs as an outcome of training: the role of computer playfulness, computer knowledge, and performance during training". Computers in Human behavior, vol. 18, no. 3, pp. 241-255, 2002.

[31] P. Bourdieu. Outline of a theory of practice. Cambridge: Cambridge University Press, 1972.

[32] C. J. Throop and K. M. Murphy. "Bourdieu and phenomenology A critical assessment". Anthropological theory, vol. 2, no. 2, pp. 185-207, 2002.

[33] P. Bourdieu. The state nobility: Elite schools in the field of power. Cambridge: Polity Press, 1996. 
[34] B. Johnson and L. Christensens. Educational research: Quantitative, qualitative and mixed approaches. Thousand Oaks, CA: Sage Publications, 2008.

[35] G. Wisker. The postgraduate research handbook: Succeed with your MA, MPhil, EdD and PhD. New York: Palgrave, 2001.

[36] C. Robson. Real world research. Oxford: Blackwell, 1993.

[37] F. Erickson. "Qualitative methods in research on teaching". In M. Wiitrock (editor), Handbook of research on teaching. New York: Macmillan, 1986.

[38] R. Pawson. "Evidence-based policy: A realist perspective". In B. Carter and C. New (editors), Making realism work: Realist social theory and empirical research. London: Routledge, 2004.

[39] L. Cassel, A. Clements, G. Davies, M. Guzdial, R. McCauley, A. McGettrick, B. Sloan, L. Snyder, P. Tymann, B. Weide, J. Cross, M. Johnson, E. Roberts, J. Whittaker, A. Wright and S. Seidman. Computer science curriculum 2008: An interim revision of $C S$ 2001. Association for Computing Machine and IEEE Computer Society, 2008.

[40] A. J. Kornecki. "Computing curricula for the 21st Century". Distributed Systems Online, IEEE, vol. 9, no. 2, pp. 2-2, 2008.

[41] K. Figl and R. Motschnig. "Researching the development of team competencies in computer science courses". In Frontiers in Education Conference, 2008. FIE 2008. 38th Annual, pp. S3F-1. IEEE, 2008.

[42] K. Hoganson. "A strategic approach to computer science curriculum". In Proceedings of the 43rd annual Southeast regional conference-Volume 1, pp. 365-370. ACM, 2005.

[43] G. Braught, C. S. Miller and D. Reed. "Core empirical concepts and skills for computer science". ACM SIGCSE Bulletin, vol. 36, no. 1, pp. 245-249, 2004.

[44] M. J. Gallivan, D. P. Truex III and L. Kvasny. "Changing patterns in IT skill sets 1988-2003: a content analysis of classified advertising". ACM SIGMIS Database, vol. 35, no. 3, pp. 64-87, 2004.

[45] L. Carter. "Ideas for adding soft skills education to service learning and capstone courses for computer science students". In Proceedings of the 42nd ACM technical symposium on Computer science education, pp. 517-522. ACM, 2011.

[46] S. Kabicher, R. Motschnig-Pitrik and K. Figl. "What competences do employers, staff and students expect from a computer science graduate?" In Frontiers in Education Conference, 2009. FIE'09. 39th IEEE, pp. 1-6. IEEE, 2009.

[47] N. Denzin. The research act: A theoretical introduction to sociological methods. New York: McGraw-Hill, 1978.

[48] A. Coffey and P. Atkinson. Making sense of qualitative data: Complementary research strategies. Thousand Oaks, CA: Sage Publications, 1996.

[49] B. G. Glaser and A. L. Strauss. The discovery of grounded theory: Strategies for qualitative research. Chicago, USA: Aldine, 1967.

[50] G. Schott and N. Selwyn. "Examining the" male, antisocial" stereotype of high computer users". Journal of Educational Computing Research, vol. 23, no. 3, pp. 291-304, 2000.
[51] C. Dweck. Mindset: The new psychology of success. New York: Ballantine Books, 2006.

[52] J. Biggs. "What the student does: teaching for enhanced learning". Higher Education Research \& $D$ velopment, vol. 18, no. 1, pp. 57-75, 1999.

[53] J. Biggs. "Aligning teaching for constructing learning". Higher Education Academy, 2003.

[54] K. Sedibe. "Dismantling apartheid education: an overview of change". Cambridge Journal of Education, vol. 28, no. 3, pp. 269-282, 1998.

[55] D. Turnbull, T. Nettlebeck, L. Ward, A. LeCouteur, A. Sarris, P. Strlan, G. Crisp, E. Palmer and L. Schneider. First year students' expectations of University study. Adelaide: University of Adelaide, 2006.

[56] B. Lam and K. Kwan. "Students' Expectations of University Education". In J. Jones and K. Kwan (editors), Evaluation of the Student Experience Project. Hong Kong: City University of Hong Kong, Centre for the Enhancement of Learning and Teaching.

[57] H. Chen, Y.-C. Wong, M.-S. Ran and C. Gilson. "Stress among Shanghai University Students The Need for Social Work Support". Journal of Social Work, vol. 9, no. 3, pp. 323-344, 2009.

[58] A. Northedge. "Enabling participation in academic discourse". Teaching in Higher Education, vol. 8, no. 2, pp. 169-180, 2003.

[59] A. J. Rodriguez. "Courage and the researcher's gaze:(Re) defining our roles as cultural warriors for social change". Journal of Science Teacher Education, vol. 12, no. 4, pp. 277-294, 2001.

[60] J. Bradbury and R. Miller. "A failure by any other name: The phenomenon of underpreparedness". South African Journal of Science, vol. 107, no. 3-4, pp. 01-08, 2011.

[61] M. Solomon. "'SA education a tragedy' - Rhodes VC". The Daily Dispatch Online, 2011. URL http: //www.dispatch.co.za/news/article/333 


\section{APPENDIX: QUESTIONNAIRE}

\section{Read the following four scenarios:}

The word used most often to describe Andrew is reliable. If you have a deadline, Andrew is the person to talk to. He is a great planner - give him a problem and he will break it into manageable portions and (when working in a team) assign it to members of the team. He is very efficient at what he does, and is good at motivating other people to do their work as well. When other team members come to him with a problem, he has the ability to see their perspective and together they work out a solution. If there was a criticism to be made of Andrew, it would be that he always plays it safe - he is not comfortable in situations that call for creative or "out of the box" thinking.

Bridget is an introvert. She is much more comfortable being out of the spot light. Typically she will only talk in a group if asked a direct question. Bridget thinks very carefully before saying anything, so prefers the time / space offered by email communication. This time gives Bridget a chance to reflect on issues / feedback and form her argument away from the pressures that come with real time communication. When Bridget does talk, people listen to what she says. She is very insightful in her comments, drawing on her analytical way of thinking.

Cynthia is extremely creative. She loves taking risks and finding things out by "playing". However, this often ends in a bit of a problem. Cynthia is extremely innovative and self motivated, but this often means that she takes so much time doing things her own way that she loses track of time and is late submitting her work. The work she comes up with though is very insightful - she often finds a new way of performing a task / completing a process.

David has a strong work ethic and is an independent and critical thinker. On top of this, David is also a great communicator. He is very happy to jump into a conversation with his perspective. He speaks with such confidence, that sometimes people believe what he says simply because he said it (although most times he is right). Not to say that he doesn't know what he's talking about, but he speaks with such authority that sometimes people don't bother checking what he says, but they take his word as law. One thing David doesn't always excel at is seeing other people's perspective. When confronted with a colleague that he believes is wrong, he can become a bit aggressive and critical.

Rate the four people in their role as a computer science student ( 1 for an ideal student to 4 for a weak student). Explain your ranking:

Andrew:

Bridget:

Cynthia:

David:

Can you think of any students in the Computer Science Department at RU who you would consider as an "ideal" student? Please explain why you consider them to be "ideal". 
For each category, circle a maximum of three (3) skills that you think are most important in a student.

Interpersonal skills:

\begin{tabular}{|c|c|c|c|c|}
\hline team attitude & team knowledge & team skills & conflict resolution & respect for others \\
\hline $\begin{array}{c}\text { work } \\
\text { independently }\end{array}$ & $\begin{array}{c}\text { intercultural } \\
\text { competence }\end{array}$ & social competence & $\begin{array}{c}\text { ability to take and see } \\
\text { other perspective }\end{array}$ & $\begin{array}{c}\text { assertive without } \\
\text { aggressive }\end{array}$ \\
\hline team player & $\begin{array}{c}\text { work under } \\
\text { supervision }\end{array}$ & $\begin{array}{c}\text { work in } \\
\text { interdisciplinary teams }\end{array}$ & open to constructive criticism \\
\hline \multicolumn{4}{|l|}{ other (please specify): }
\end{tabular}

Leadership skills:

\begin{tabular}{|c|c|c|c|c|c|}
\hline initiative & innovative & decision making & dedication & influential & ambitious \\
\hline
\end{tabular}

Self management:

\begin{tabular}{|c|c|c|c|c|c|}
\hline self motivated & enthusiastic & attention to detail & self directed & responsible & lifelong learning \\
\hline other (please specify):
\end{tabular}

Thinking skills:

\begin{tabular}{|c|c|c|c|}
\hline analysis and synthesis & innovative & entrepreneurial & abstract thinking \\
\hline creative & problem solving & empirical skills & $\begin{array}{c}\text { independent critical } \\
\text { thinking }\end{array}$ \\
\hline other (please specify):
\end{tabular}

Workload management:

\begin{tabular}{|c|c|c|c|c|c|}
\hline $\begin{array}{c}\text { work under } \\
\text { pressure }\end{array}$ & $\begin{array}{c}\text { time } \\
\text { management }\end{array}$ & $\begin{array}{c}\text { effective work } \\
\text { habits }\end{array}$ & $\begin{array}{c}\text { ability to work well } \\
\text { on multiple } \\
\text { complex projects }\end{array}$ & organized & Planning \\
\hline
\end{tabular}

Information handling:

\begin{tabular}{|c|c|c|c|}
\hline $\begin{array}{c}\text { good oral } \\
\text { communication }\end{array}$ & $\begin{array}{c}\text { good at working at an } \\
\text { abstract level }\end{array}$ & $\begin{array}{c}\text { good written } \\
\text { communication }\end{array}$ & $\begin{array}{c}\text { information management } \\
\text { skills }\end{array}$ \\
\hline research skills & detail oriented whilst maintain overall vision and focus & see the larger picture \\
\hline other (please specify): & \multicolumn{2}{|l}{} \\
\hline
\end{tabular}

Personal qualities:

\begin{tabular}{|c|c|c|c|c|}
\hline credible & accountable & responsible & insightful & visionary \\
\hline creative & persevere & practical & confident & patient \\
\hline empathetic & work ethic & $\begin{array}{c}\text { critical and self } \\
\text { critical abilities }\end{array}$ & $\begin{array}{c}\text { ability to work } \\
\text { autonomously }\end{array}$ & $\begin{array}{c}\text { entrepreneurial } \\
\text { spirit }\end{array}$ \\
\hline initiative & passion for work & passion for quality & social modesty & Independent \\
\hline \multicolumn{4}{|l}{} \\
\hline
\end{tabular}

Skills for handling unknown:

\begin{tabular}{|c|c|c|c|c|c|}
\hline risk taking & resilient & problem solving & reasoning skills & analytical skills & adaptable \\
\hline flexible & $\begin{array}{c}\text { open } \\
\text { mindedness }\end{array}$ & $\begin{array}{c}\text { risk } \\
\text { management }\end{array}$ & compromising & $\begin{array}{c}\text { ability to deal with } \\
\text { new technologies }\end{array}$ & efficiency \\
\hline \multicolumn{2}{|l}{ other (please specify): }
\end{tabular}

